\title{
Staphylococcus haemolyticus disseminated among neonates with bacteremia in a neonatal intensive care unit in Rio de Janeiro, Brazil ${ }^{\text {is }}$
}

\author{
Paula Marcele Afonso Pereira ${ }^{a}$, Vanessa Batista Binatti ${ }^{a}$, Bruna Pinto Ribeiro Sued ${ }^{a}$, Juliana Nunes Ramos ${ }^{a, c}$, \\ Renata Stavracakis Peixoto ${ }^{\mathrm{a}, \mathrm{b}}$, Cláudio Simões ${ }^{\mathrm{b}}$, Eduardo Almeida de Castro ${ }^{\mathrm{a}}$, \\ José Luís Muniz Bandeira Duarte ${ }^{\mathrm{a}}$, Verônica Viana Vieira ${ }^{\mathrm{c}}$, Raphael Hirata Jr. ${ }^{\mathrm{a}}$, Kátia Regina Netto Santos ${ }^{\mathrm{b}}$, \\ Ana Luíza Mattos-Guaraldi ${ }^{a}$, , José Augusto Adler Pereira ${ }^{a}$ \\ a Faculdade de Ciências Médicas, Universidade do Estado do Rio de Janeiro \\ ${ }^{\mathrm{b}}$ Instituto de Microbiologia Prof. Paulo de Góes, Universidade Federal do Rio de Janeiro \\ ' Fundação Oswaldo Cruz, Instituto Nacional de Controle de Qualidade em Saúde - INCQS -Departamento de Microbiologia, Rio de Janeiro, RJ, Brazil
}

\section{A R T I C L E I N F O}

\section{Article history:}

Received 11 March 2013

Received in revised form 26 May 2013

Accepted 4 June 2013

Available online 28 October 2013

\section{Keywords:}

Staphylococcus haemolyticus

Multiresistance

PFGE

Biofilm

Neonates

Bacteremia

\begin{abstract}
A B S T R A C T
Oxacillin-resistant Staphylococcus haemolyticus (ORSH) was found as the most prevalent (77.5\%) species of coagulase-negative staphylococci associated with bacteremia in neonates making use of intravenous catheters in an intensive care unit of a Brazilian teaching hospital. Thirty-one blood isolates were confirmed as $S$. haemolyticus by sequencing of the $16 \mathrm{~S}$ and clustered in 6 pulsed-field gel electrophoresis types (with $58 \%$ of the strains belonging to 2 predominant types B and D). S. haemolyticus was mostly oxacillin-resistant (90.3\%) displaying multiresistance profiles (70.4\%). However, the mecA gene was undetected in $22.6 \%$ strains. ORSH exhibited slime production on Congo-Red agar (67.7\%), adherence to polystyrene (96.7\%), and glass (87\%) surfaces. Interestingly, ica-operon was detected in $58 \%$ strains, mostly belonging to the B, D, and $\mathrm{F}$ genotypes, which is a significantly higher percentage when compared to other studies conducted at different parts of the globe. Data indicated that ica operon and biofilm-forming ORSH are endemic in Brazilian nosocomial environment.
\end{abstract}

(C) 2014 Elsevier Inc. All rights reserved.

\section{Introduction}

Among the coagulase-negative staphylococci (CoNS), Staphylococcus haemolyticus plays an important role in hospital-acquired opportunistic infections worldwide (Barros et al., 2012; Botelho et al., 2012; Jain et al., 2004; Monsen et al., 2005; Nystrom et al., 1992; Tuo et al., 1995; Voronina et al., 2011). S. haemolyticus is second only to Staphylococcus epidermidis in its frequency of isolation from human blood cultures (Falcone et al., 2006; Ing et al., 1997). The pathogen may also cause peritonitis, otitis, urinary tract infections, and septicemia (Kumari et al., 2001). Oxacillin-resistant S. haemolyticus (ORSH) strains have been also associated with foreign body infections (Falcone et al., 2006).

S. haemolyticus is also among the CoNS that colonize and cause bacteremia in neonatal intensive care units (NICUs) in many countries (Bjorkqvist et al., 2002; Bradford et al., 2006; Foka et al., 2006; Klingenberg et al., 2007; Neumeister et al., 1995; Tuo et al., 1995; Voronina et al., 2011). In Greece, the analysis of clonality of slimeproducing methicillin-resistant CoNS (MR-CoNS) disseminated among pre-term neonates revealed that all MR-CoNS strains were

\footnotetext{
Disclosure Statement: No competing financial interests exist.

* Corresponding author. Fax: +55-21-2868-8376.

E-mail address: guaraldi@uerj.br (A.L. Mattos-Guaraldi).
}

multiresistant, and $89 \%$ produced slime. Ten of 16 S. haemolyticus isolates belonged to a single clone (Foka et al., 2006). In Norway, a study of persistent strains of CoNS in a single neonatal unit over a 12year period showed that only $1 \mathrm{~S}$. haemolyticus cluster appeared to selectively colonize and infect the most extreme pre-term infants (Klingenberg et al., 2007). In India, S. haemolyticus (36\%) and S. epidermidis (35\%) were indicated as the most frequent CoNS species encountered in a NICU (Jain et al., 2004; Mehta et al., 1991) and as the only pathogens from infants that developed septicemia due to CoNS. Forty-five percent of these CoNS strains were slime producers (Mehta et al., 1991).

\section{Objectives}

Multiple selective factors, including antibiotic resistance, biofilm formation, and surface proteins with adhesive properties, increase the ability of CoNS to persist in a hospital environment (Klingenberg et al., 2007). Hence, in the present study, S. haemolyticus strains were isolated from blood cultures of infants making use of intravenous catheters in the NICU, over a 3-year period. Microorganisms were analyzed to determine their clonal distribution by pulsed-field gel electrophoresis (PFGE), antibiotic resistance patterns, biofilm production, and the prevalence of mecA and icaA genes associated with oxacillin resistance and biofilm formation, respectively. 


\section{Materials and methods}

\subsection{Patients and origin of CoNS strains}

A total of 47 blood culture isolates of CoNS were obtained from 40 neonates admitted to NICU of a teaching hospital, Rio de Janeiro, Brazil, over the period from 2008 to 2010. Thirty-seven of them (92.5\%) were diagnosed as bacteremia isolates and 03 (7.5\%) as contaminants. Invasive strains were collected from the following clinical groups: a) patients making use of indwelling catheter $(n=40)$; b) patients with clinical evidence of infection and submitted to empiric antibiotic therapy with vancomycin or gentamycin $(n=37)$; c) patients without clinical evidence of infection ( $n=03)$; d) patients with fever $(n=25)$; d) patients without fever $(n=13)$; and e) premature patients $(n=2)$.

The assessment of clinical aspects was performed through a review of the medical records. The regional committee for medical research ethics approved the collection and analysis of patient data. Patients with $1(n=33)$ or $2(n=07)$ positive blood cultures were interpreted as infected when a CoNS was isolated from blood cultures in which there was a suspicion of infection and the physician considered it clinically significant to immediately start an empiric antimicrobial therapy. The diagnosis of infection was staged according to the classification of the Centers for Disease Control and Prevention (CDC, 1992). The isolates categorized as contaminants were not included in this study.

The control isolates used for the phenotypic characterization, antimicrobial susceptibility tests, PCRs, and the biofilm assays were S. haemolyticus ATCC 29970, S. epidermidis ATCC 35984, S. epidermidis ATCC 12228, S. epidermidis ATCC 14990, Staphylococcus hominis ATCC 27844, Staphylococcus saprophyticus ATCC 15305, Staphylococcus warneri ATCC 10209, Staphylococcus aureus ATCC 12600, S. aureus ATCC 29213, S. aureus ATCC 33591 and S. aureus ATCC 25923.

\subsection{Phenotypic procedures}

\subsubsection{Phenotypic characterization}

A simplified method using 9 tests was carried out as described by Iorio et al. (2007): 2 susceptibility tests using $5 \mu \mathrm{g}$ novobiocin and 100 $\mu \mathrm{g}$ desferrioxamine disks; tests that detect the production of clumping factor, PYR, urease, and alkaline phosphatase as well as acid production from D-mannose, D-trehalose and D-xylose.

\subsubsection{Antibiotic susceptibility testing}

3.2.2.1. Disk diffusion test. Antibiotic susceptibility testing by the disk diffusion method was performed according the guidelines of the Clinical and Laboratory Standards Institute (CLSI, 2010), except for mupirocin (Fuchs et al., 1990). Sixteen antibiotics (purchased from CECON; São Paulo, Brazil, and Oxoid, Basingstoke, England) were tested: oxacillin (Oxa), cefoxitin (Cfx), penicillin (P), ceftazidime (Caz), gentamycin (Gen), neomycin (Neo), tobramycin (Tob), ertapenem (Etp), meropenem (Mer), ciprofloxacin (Cip), erythromycin (Ery), clindamycin (Clin), chloramphenicol (Clo), mupirocin (Mup), tetracycline (Tet), and vancomycin (Van).

3.2.2.2. MIC of oxacillin and vancomycin. The MICs of oxacillin (Sigma, St. Louis, MO, USA) and vancomycin (Oxoid, Basingstoke, England) were evaluated by the broth microdilution method (CLSI, 2010, 2012). The concentrations ranged from 0.25 to $512 \mu \mathrm{g} / \mathrm{mL}$ for oxacillin and from 0.25 to $256 \mu \mathrm{g} / \mathrm{mL}$ for vancomycin. The plates were incubated at $35^{\circ} \mathrm{C}$ for $24 \mathrm{~h}$.

\subsection{Biofilm testing}

\subsubsection{Slime production assays for}

Qualitative detection of slime production was studied by culturing the strains on Congo Red Agar plates (CRA; Sigma Chemical Company, St Louis, MO, USA) as described previously (Chaieb et al., 2005;
Freeman et al., 1989). Inoculated CRA plates (0.8 g Congo red mixed with $36 \mathrm{~g}$ sucrose in $1 \mathrm{~L}$ of brain heart infusion agar) were incubated for $24 \mathrm{~h}$ at $37{ }^{\circ} \mathrm{C}$ under aerobic conditions and followed overnight at room temperature. Slime-positive variants appeared as reddish-black colonies with a rough, dry, and crystalline consistency on CRA, whereas slime-negative strains developed pinkish-red, smooth colonies with a darkening at the center. S. epidermidis strains ATCC 35984 and ATCC 12228 were used as positive and negative controls, respectively.

\subsubsection{Glass surface adherence assay}

Briefly, microorganisms were inoculated in glass tubes ( 13 by 100 $\mathrm{mm}$ ) containing $4 \mathrm{~mL}$ of Trypticase Soy Broth (TSB) and incubated for $48 \mathrm{~h}$ at $37^{\circ} \mathrm{C}$ without shaking. The tubes were gently shaken for $5 \mathrm{~s}$, and the supernatants containing bacterial cells that were nonadherent to the surfaces of the glass tubes were discarded. TSB $(4 \mathrm{~mL})$ was then added, and the tubes were re-incubated for $48 \mathrm{~h}$. This procedure was repeated twice. The glass-adherent bacteria created a confluent coat of cells on sides of the tube (Moreira et al., 2003).

\subsubsection{Plastic surface adherence assay}

Semi-quantitative adherence assay in polystyrene microtiter plates was performed as previously described by Stepanovic et al. (2000). Briefly, CoNS strains were cultivated overnight in TSB medium, and $200 \mu \mathrm{L}$ of each bacterial suspension was used to inoculate sterile, 96well polystyrene microtiter plates (Greiner, Frickenhausen, Germany). After incubation for $24 \mathrm{~h}$ at $37^{\circ} \mathrm{C}$, the wells were gently washed twice with $200 \mu \mathrm{L}$ of sterile phosphate-buffered saline. The plates were air dried, and the remaining surface-adsorbed cells of the individual wells were stained with $0.1 \%$ crystal violet for $30 \mathrm{~s}$. Absorbance was measured with a Micro-ELISA Autoreader (Titertek Multiscan) at $\lambda=$ $490 \mathrm{~nm}$. The well, to which sterile TSB lacking bacterial cells was added, served as control; the value for this well was subtracted from the experimental readings. Each assay was performed in triplicate. The cut-off $\mathrm{OD}\left(\mathrm{OD}_{\mathrm{C}}\right)$ for the microtiter plate test was defined as $3 \mathrm{SDs}$ above the mean OD of the negative control. Based upon the ODs of bacterial films, microorganisms were classified as non-adherent $(\mathrm{OD} \leq$ $\left.\mathrm{OD}_{\mathrm{C}}\right)$ and adherent $\left(\mathrm{OD}_{\mathrm{C}}<\mathrm{OD}\right)$.

\subsection{Genotyping procedures}

\subsubsection{Multiplex PCR assay (mPCR) to identify methicillin-resistant S. haemolyticus}

An mPCR to simultaneously identify S. aureus, S. haemolyticus, and S. epidermidis species and to determine methicillin resistance by the presence of gene mecA was performed in accordance to previously described methods (Iorio et al., 2011; Potter et al., 2009; Santos et al., 1999; Schuenck et al., 2008). The primers and amplicons used in this study are listed in Table 1.

\subsection{Gene amplification and sequencing}

S. haemolyticus identification was reconfirmed by sequencing of the 16S rRNA gene of representative strains (SH6, SH8, SH9, SH10, SH12). DNA extraction, primer design, the PCR parameters employed to amplified 16S rRNA gene, and sequencing of amplified PCR products following their purifications were also performed as previously described by Baio et al. (2013). The sequencing reactions were performed with Big Dye Terminator v 3.1 cycle sequencing kit (Applied Biosystems) on an ABI-3730 Automated DNA Sequencer (Applied Biosystems) by standard protocols. The 16S rRNA gene sequences were compared to those available in the National Center for Biotechnology Information (http://www.ncbi.nlm.nih.gov) using the BLAST algorithm and the Ribosomal Database Project (RDP-II) (http:// rdp.cme.msu.edu/html). 
Table 1

Primers used in this study.

\begin{tabular}{llll}
\hline Primers & $\begin{array}{l}\text { Sequence of forward and } \\
\text { reverse primers } \text { 5 }^{\prime} \rightarrow \text { 3 }^{\prime}\end{array}$ & $\begin{array}{l}\text { Product } \\
\text { size }(\mathrm{bp})\end{array}$ & References \\
\hline SH1 & $\begin{array}{l}\text { GGTCGCTTAGTCGGAACAAT } \\
\text { SH2 }\end{array}$ & 285 & Schuenck et al., 2008 \\
SE1 & CAGGAGCAATCTCATCACCT & & Iorio et al., 2011 \\
SE2 & CTGTAGAGTGACATGAGAGC & 218 & Santos et al., 1999 \\
MRS1 & TAGAAATGACTGAACGTCCG & 154 & Potter et al., 2009 \\
MRS2 & TTGCGATCAATGTACCTAG & & \\
$\begin{array}{l}\text { icaAF } \\
\text { icaAR }\end{array}$ & CGATGGGCTCAAGGTGG & 287 & \\
\hline
\end{tabular}

\subsubsection{DNA fingerprinting by PFGE}

Chromosomal DNA preparation and PFGE analysis were performed as described previously (Nunes et al., 2005; Vivoni et al., 2006). PFGE banding patterns were analyzed using visual comparison among the strains and with the aid of automated analysis using the Bionumerics program, version 6.0. The Dice similarity coefficients were calculated with a band position tolerance of $1.5 \%$, and the UPGMA method was applied for clusters analysis. Isolates were first assigned to PFGE types, using $80 \%$ band-based similarity coefficients as cut-off values. Banding patterns were classified according to the criteria described by Van Belkum et al. (2007). PFGE types were identified by letters, and subtypes were identified by letters followed by a numeric subscript.

\subsection{Statistical analysis}

The chi-square tests and Fisher exact tests were used to assess the statistical significance for a confidence level of $95 \%$; $P$-value $<.05$ was considered statistically significant.

\section{Results}

\subsection{Identification of S. haemolyticus strains}

Phenotypic tests identified CoNS strains as S. haemolyticus (77.5\%), S. epidermidis ( $15 \%$ strains), S. captis ( $5 \%$ strains), and S. warneri ( $2.5 \%$ strain). The $31 \mathrm{~S}$. haemolyticus blood isolates identified by the phenotypic assays were confirmed by mPCR and 16S rRNA sequencing. Genbank accession numbers for $16 \mathrm{~S}$ rRNA genes sequences of $S$. haemolyticus strains were deposited under the bank with submitting numbers 1632716, 1632721, 1632727, 1632729, and 1632731 on GenBank database.

\subsection{Determination of clonal distribution by PFGE}

PFGE analysis showed the presence of 12 restriction profiles clustered in 6 pulse types: $\mathrm{A}(n=4 ; 12.9 \%), \mathrm{B}(n=10 ; 32.2 \%), \mathrm{C}$ ( $n=$ $5 ; 16.1 \%), \mathrm{D}(n=8 ; 25.8 \%), \mathrm{E}(n=1 ; 3.2 \%)$, and $\mathrm{F}(n=3 ; 9.6 \%)$ (Fig. 1 and Table 2). Isolates showing a similarity coefficient $\geq 80 \%$ were considered genetically PFGE related. Several clinical isolates were classified as belonging to the same clonal subtype A'1 $(n=01), A^{\prime} 2(n$ $=02), \mathrm{A}^{\prime} 3(n=01), \mathrm{B}^{\prime} 1(n=05), \mathrm{B} 2(n=05), \mathrm{C}^{\prime} 1(n=02), \mathrm{C}^{\prime} 2(n=$ $03), \mathrm{D}^{\prime} 1(n=05), \mathrm{D}^{\prime} 2(n=03), \mathrm{F}^{\prime} 1(n=01)$, and F'2 $(n=02)$ (Tables 2 and 3). The 16S rRNA sequences from 5 representative PFGE type strains exhibited highest similarity values to the type strain of S. haemolyticus, ranges of $99.15 \%$ to $99.54 \%$.

\subsection{Antimicrobial susceptibility profiles}

Results of the disk diffusion tests shown in Fig. 2, Tables 2, and 3 shown multiresistance to varied antimicrobial agents in $87 \%$ of S. haemolyticus strains isolated from blood of neonates making use of intravenous catheters. Antimicrobial susceptibility profiles were independent of PFGE types and subtypes; 28 out of 31 tested strains (90.3\%) were phenotypically resistant to oxacillin (ORSH). Oxacillin-resistant isolates were also resistant to representative drugs from 4 to 6 nonbeta-lactam drug classes. The resulting MICs for oxacillin (range: $0.25-$ $512 \mu \mathrm{g} / \mathrm{mL}$; oxacillin-resistant mean values: $356.07 \pm 211.9 \mu \mathrm{g} / \mathrm{mL}$ ) were compared to disk diffusion zone diameters and to mecA gene detection by PCR $(P=.028)$. MICs for oxacillin ranging from $>4$ to $<128$ $\mu \mathrm{g} / \mathrm{mL}$ were not observed for $S$. haemolyticus strains included in this study. Interestingly, most of the S. haemolyticus strains ( $n=27 ; 70.4 \%$ ) showed high resistance levels to oxacillin (MIC values $\geq 128 \mu \mathrm{g} / \mathrm{mL}$ ). With the used pair of primers, we could not observe an agreement between high MICs values and mecA detection, since the mecA gene was not detected for 2 (6.4\%) ORSH isolates (SH-27, SH-28 strain) with MICs reported as $\geq 128 \mu \mathrm{g} / \mathrm{mL}$. The presence of mecA gene was observed in $77.4 \%(n=24)$ of S. haemolyticus strains belonging to PFGE types A ( $n=$

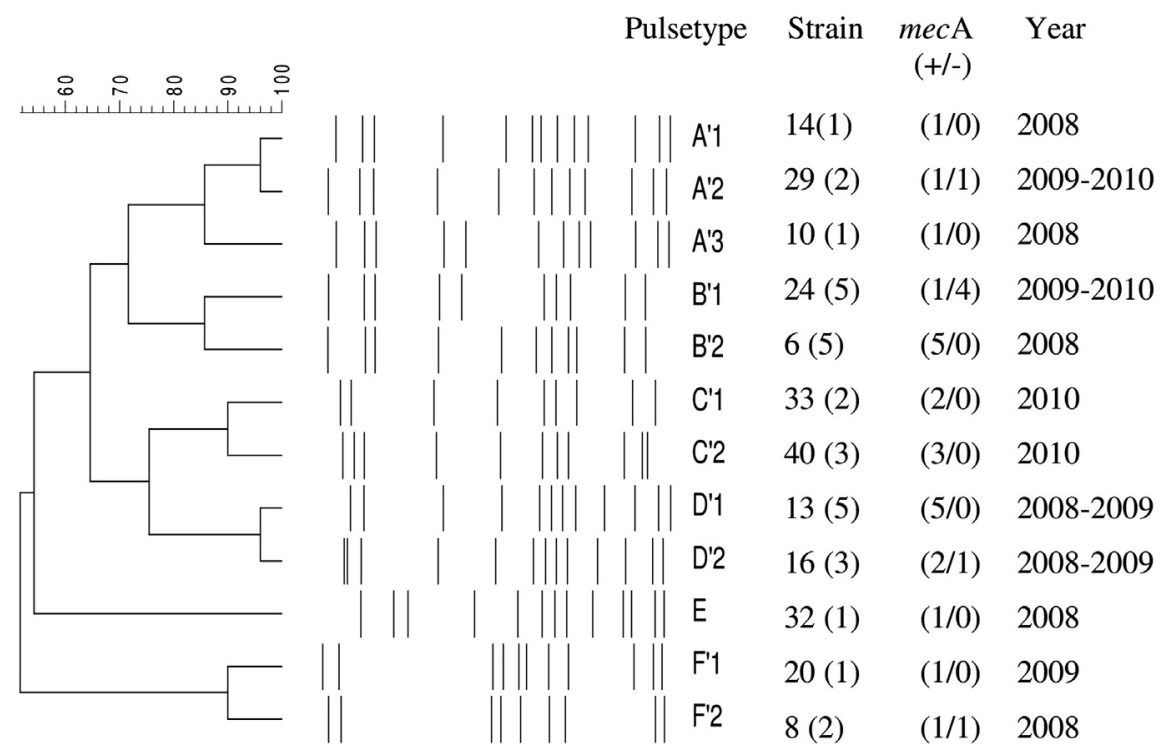

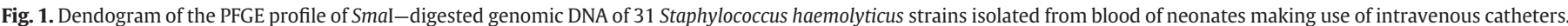

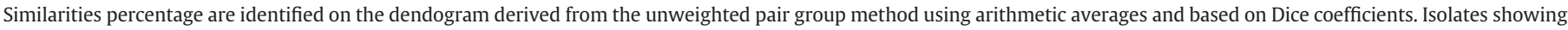

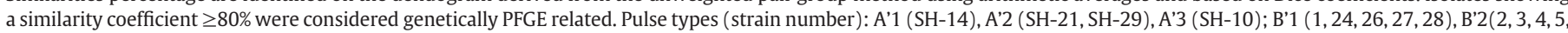

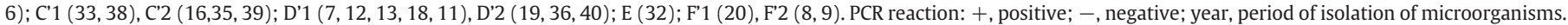


Table 2

Microbiological and genetic properties of Staphylococcus haemolyticus strains isolated from blood of neonates making use of intravenous catheters.

\begin{tabular}{|c|c|c|c|c|c|c|c|c|}
\hline $\begin{array}{l}\text { Strain } \\
\text { number }\end{array}$ & $\begin{array}{l}\text { Year of } \\
\text { isolation }\end{array}$ & $\begin{array}{l}\text { Biofilm formation } \\
\text { CRA/G/P }\end{array}$ & $\begin{array}{l}\text { icaA } \\
\text { Gene }\end{array}$ & $\begin{array}{l}\text { Vancomycin } \\
\text { MIC ( } \mu \mathrm{g} / \mathrm{mL})\end{array}$ & $\begin{array}{l}\text { Oxacillin MIC } \\
(\mu \mathrm{g} / \mathrm{mL})\end{array}$ & $\begin{array}{l}\text { Oxacillin } \\
\text { susceptibility }\end{array}$ & $\begin{array}{l}\text { mecA } \\
\text { gene }\end{array}$ & $\begin{array}{l}\text { PFGE } \\
\text { type }\end{array}$ \\
\hline SH-14 & 2008 & $+/+/+$ & - & 4 & 512 & $\mathrm{R}$ & + & A1 \\
\hline SH-21 & 2009 & $-1+1-$ & - & 4 & 512 & $\mathrm{R}$ & + & A2 \\
\hline SH-29 & 2010 & $-1+1+$ & - & 4 & 4 & $\mathrm{R}$ & - & A2 \\
\hline SH-10 & 2008 & $+/+/+$ & + & 4 & 512 & $\mathrm{R}$ & + & A3 \\
\hline $\mathrm{SH}-1$ & 2009 & $+/+/+$ & + & 8 & 512 & $\mathrm{R}$ & + & B1 \\
\hline SH-24 & 2009 & $-1-1+$ & + & 4 & 0.25 & $\mathrm{R}$ & - & B1 \\
\hline SH-26 & 2010 & $+/+/+$ & + & 2 & 0.25 & $S$ & - & B1 \\
\hline SH-27 & 2010 & $+/+/+$ & + & 4 & 128 & $\mathrm{R}$ & - & B1 \\
\hline SH-28 & 2010 & $+/+/+$ & + & 4 & 128 & $\mathrm{R}$ & - & B1 \\
\hline SH-2 & 2008 & $+/+/+$ & + & 2 & 512 & $\mathrm{R}$ & + & B2 \\
\hline $\mathrm{SH}-3$ & 2008 & $+1+1+$ & + & 2 & 512 & $\mathrm{R}$ & + & B2 \\
\hline $\mathrm{SH}-4$ & 2008 & $+/+/+$ & + & 2 & 512 & $\mathrm{R}$ & + & B2 \\
\hline SH-5 & 2008 & $+/+/+$ & + & 4 & 512 & $\mathrm{R}$ & + & B2 \\
\hline SH-6 & 2008 & $+/+/+$ & + & 2 & 128 & $\mathrm{R}$ & + & B2 \\
\hline SH-33 & 2010 & $+/+/+$ & - & 2 & 0.25 & $\mathrm{~S}$ & + & $\mathrm{C} 1$ \\
\hline SH-38 & 2010 & $+/+/+$ & - & 2 & 256 & $\mathrm{R}$ & + & $\mathrm{C} 1$ \\
\hline SH-16 & 2009 & $+/+/+$ & + & 4 & 512 & $\mathrm{R}$ & + & $\mathrm{C} 2$ \\
\hline SH-35 & 2010 & $+/+/+$ & - & 4 & 1 & $\mathrm{R}$ & + & $\mathrm{C} 2$ \\
\hline SH-39 & 2010 & $+/+/+$ & - & 2 & 4 & $\mathrm{R}$ & + & $\mathrm{C} 2$ \\
\hline SH-7 & 2008 & $-1+1+$ & + & 4 & 4 & $\mathrm{R}$ & + & D1 \\
\hline SH-12 & 2008 & $+/+/+$ & + & 4 & 512 & $\mathrm{R}$ & + & D1 \\
\hline SH-13 & 2008 & $+/+/+$ & - & 4 & 512 & $\mathrm{R}$ & + & D1 \\
\hline SH-18 & 2009 & $-1-/+$ & + & 2 & 512 & $\mathrm{R}$ & + & D1 \\
\hline SH-11 & 2008 & $+/+1+$ & + & 2 & 512 & $\mathrm{R}$ & + & D1 \\
\hline SH-19 & 2009 & $+/-/+$ & - & 4 & 512 & $\mathrm{R}$ & + & D2 \\
\hline SH-36 & 2010 & $-1-1+$ & - & 4 & 0.25 & $\mathrm{~S}$ & - & D2 \\
\hline SH-40 & 2010 & $-/+/+$ & - & 4 & 256 & $\mathrm{R}$ & + & D2 \\
\hline SH-32 & 2010 & $-/+/+$ & - & 2 & 1 & $\mathrm{R}$ & - & $\mathrm{E}$ \\
\hline SH-20 & 2009 & $-1+1+$ & - & 2 & 512 & $\mathrm{R}$ & + & $\mathrm{F} 1$ \\
\hline SH-8 & 2008 & $+/+/+$ & + & 4 & 512 & $\mathrm{R}$ & + & $\mathrm{F} 2$ \\
\hline SH-9 & 2008 & $-1+1+$ & + & 4 & 512 & $\mathrm{R}$ & + & $\mathrm{F} 2$ \\
\hline
\end{tabular}

$\mathrm{G}=$ Adherence to glass; $\mathrm{P}=$ Adherence polystyrene; $+=$ Positive; $-=$ Negative. Experiments were performed in triplicate.

$3 ; 12.5 \%), \mathrm{B}(n=6 ; 25 \%), \mathrm{C}(n=5 ; 20.8 \%), \mathrm{D}(n=7 ; 29.1 \%), \mathrm{F}(n=3$; $12.5 \%)$, but not $\mathrm{E}(n=0)$. Data showed that most of the strains of PFGE types A, B, and D gave positive results for the mecA gene. The presence of mecA gene was observed in all strains tested of PFGE types $\mathrm{C}$ and $\mathrm{F}$. Moreover, results of the disk diffusion test demonstrated $61.2 \%$ resistance to gentamicin and $100 \%$ susceptibility to vancomycin of all ORSH and oxacillin-sensitive Staphylococcus haemolyticus strains. Eighteen S. haemolyticus strains (58\%) showed MIC to vancomycin of 4 $\mu \mathrm{g} / \mathrm{mL}$, and only the SH-1 strain showed MIC of $8 \mu \mathrm{g} / \mathrm{mL}$ (medium of $3.355 \pm 1.284 \mu \mathrm{g} / \mathrm{mL})$.

\subsection{Slime production and adherence to abiotic surfaces}

Microbiological and genetic properties of S. haemolyticus strains isolated from blood samples of neonates making use of intravenous catheters are displayed in Tables 2 and 3. Slime production, adherence to hydrophilic (glass), and/or hydrophobic (polystyrene) abiotic surfaces were observed for $S$. haemolyticus, but with different profiles. Twenty-one strains gave (67.7\%) simultaneous positive results for these 3 tests. However, we did not observe strains that gave simultaneous negative results for these 3 tests. Slime production evaluated by the CRA method was observed for $67.7 \%$ strains; $32.3 \%$ S. haemolyticus blood isolates were non-slime producers. Most of the strains tested (87\%) were adherent to glass surfaces. All S. haemolyticus isolates, except the SH-21 strain, adhered to polystyrene surfaces commonly formed biofilms. No correlation among the results of CRA, polystyrene, and glass adherence tests was partially observed $(P=.534)$. The SH-21 strain was glass positive but polystyrene negative. Interestingly, we observed only 1 CRA-positive and glass-negative isolate (SH-19 strain), while 7 (SH-

Table 3

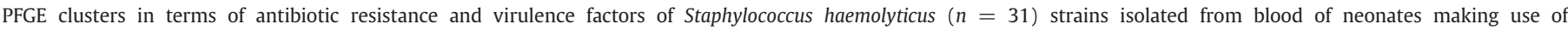
intravenous catheters.

\begin{tabular}{|c|c|c|c|c|c|c|c|}
\hline \multirow[t]{2}{*}{ Bacterial characteristics } & \multirow{2}{*}{$\begin{array}{l}\text { Total number } \\
\text { of strains (\%) }\end{array}$} & \multicolumn{6}{|c|}{ Number of strains in PFGE clusters } \\
\hline & & Type $\mathrm{A}$ Total $=4$ & Type B Total $=10$ & Type $C$ Total $=5$ & Type D Total $=8$ & Type E Total $=1$ & Type F Total $=3$ \\
\hline \multicolumn{8}{|l|}{ Genes } \\
\hline mecA-positive & $24(77.4)$ & 3 & 6 & 5 & 7 & 0 & 3 \\
\hline$i c a A$ & $18(58)$ & 1 & 10 & 1 & 4 & 0 & 2 \\
\hline Oxacillin resistance & $28(90.3)$ & 4 & 9 & 4 & 7 & 1 & 3 \\
\hline \multicolumn{8}{|l|}{ MICs } \\
\hline Oxacillin (BMD test) $\geq 512 \mu \mathrm{g} / \mathrm{mL}$ & $17(54.8)$ & 3 & 5 & 1 & 5 & 0 & 3 \\
\hline Vancomycin (BMD test) $\geq 4 \mu \mathrm{g} / \mathrm{mL}$ & $18(58)$ & 3 & 5 & 2 & 6 & 0 & 2 \\
\hline \multicolumn{8}{|c|}{ Biofilm formation } \\
\hline CRA & $21(67.7)$ & 2 & 9 & 5 & 4 & 0 & 1 \\
\hline Glass & $27(87)$ & 4 & 9 & 5 & 5 & 1 & 3 \\
\hline Polystyrene & $30(96.7)$ & $3^{\mathrm{a}}$ & 10 & 5 & 8 & 1 & 3 \\
\hline Year of isolation & 2008, 2009, 2010 & $2008,2009,2010$ & 2008, 2009, 2010 & 2009, 2010 & 2008, 2009, 2010 & 2010 & 2008, 2009 \\
\hline
\end{tabular}

$\mathrm{BMD}=$ Broth microdilution test.

a $\mathrm{SH}-21$ strain (subtype A2) was polystyrene negative. 


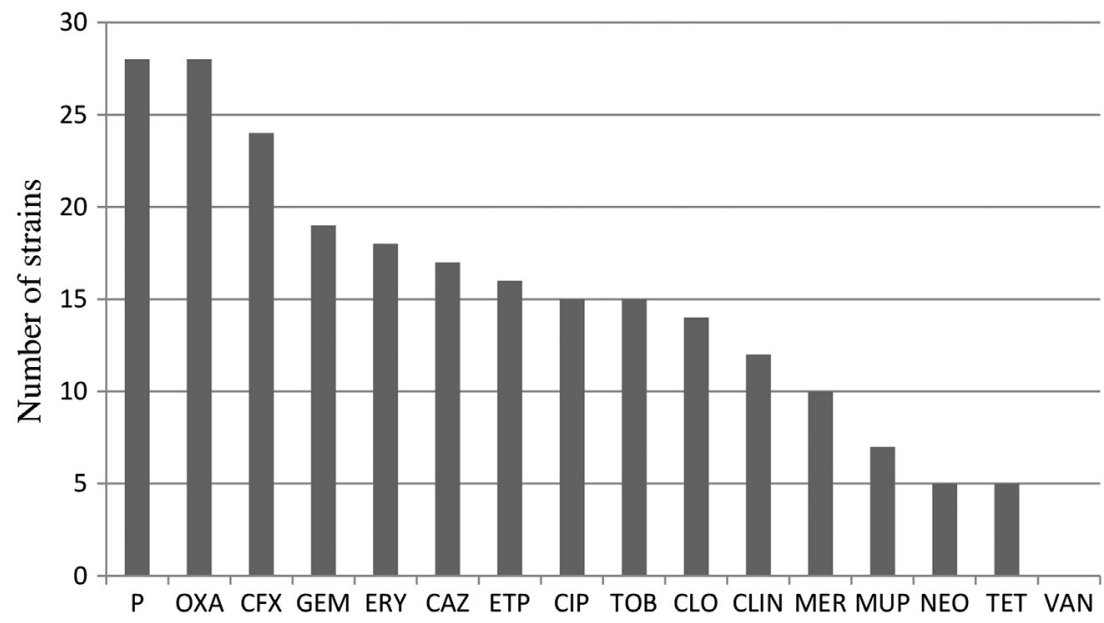

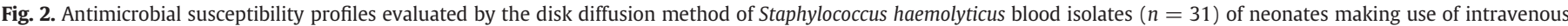

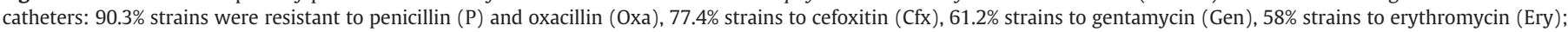

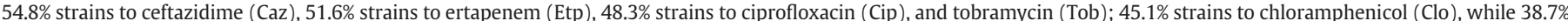

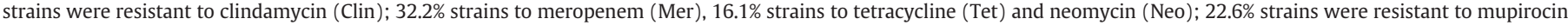
(Mup) and 100\% strains were susceptible to vancomycin (Van).

\section{1, SH-29, SH-07, SH-09, SH-32, SH-40, SH-20 strains) isolates were} CRA negative and glass positive.

Microorganisms from PFGE types B and C showed the highest proportion of strains with simultaneous ability to produce slime and/ or biofilm in all 3 abiotic surfaces tested (CRA, glass, and polystyrene). The presence of icaA gene positive was observed in $58 \%$ of S. haemolyticus blood isolates. No correlation was observed among biofilm formation on abiotic surfaces, oxacillin phenotypic resistance (glass $P=.422$; polystyrene $P=.822$ ), and the presence of mecA gene (glass $P=.120$; polystyrene $P=.754$ ) and icaA gene (glass $P=.195$; polystyrene $P=.654$ )

\section{Discussion}

In many countries, S. haemolyticus is second to S. epidermidis in its frequency of isolation from newborns (Bjorkqvist et al., 2002). The number of infections caused by CoNS has dramatically increased as the management of patients in the NICUS has become more dependent on invasive procedures and indwelling devices (Brodie et al., 2000). Some studies of the clonality of ORSH responsible of epidemic infections in NICU suggested that ORSH neonatal infections are caused by a limited number of clones (Kazembe et al., 1993; Low et al., 1992).

PFGE typing showed that the $S$. epidermidis isolates regarded as inducers of sepsis were more homogeneous than isolates considered contaminants (Bjorkqvist et al., 2002). The occurrence of a dominating genotypic group among the sepsis isolates of $S$. epidermidis may represent strains with higher invasive capacity (Chu et al., 2011). Recently, cluster and phylogenetic analysis of CoNS strains isolated in hospitals emphasized the high adaptive ability of some nosocomial strains of S. haemolyticus that circulate in hospitals in the Russian Federation and threaten both neonates and hospitalized adult patients (Voronina et al., 2011).

In the present study, $S$. haemolyticus was the most prevalent species $(77.5 \%)$ isolated from infants with bacteremia and subjected to therapy with vancomycin and/or gentamicin in a Brazilian NICU, as previously observed in India (Jain et al., 2004; Mehta et al., 1991). PFGE results revealed 6 pulse types $(A, B, C, D, E$, and $F$ ) indicating a genetic diversity among these $S$. haemolyticus strains during the period of 2008-2010. Pulse types A, B, D, and E were observed during the 3 years of the study. Most of the types were mainly observed in 2008 , while type $C$ was observed mainly in $2010(P<.358)$. Among the S. haemolyticus isolates, $18(58 \%)$ strains belonged to the 2 predominant pulse types, $\mathrm{B}(n=10)$ and $\mathrm{D}(n=08)$. Similar to data described in the Russian Federation (Voronina et al., 2011), the presence of 2 predominant PFGE types (B and D) indicated the adaptive ability of some nosocomial strains of S. haemolyticus to circulate in this hospital located in Rio de Janeiro and to infect neonates hospitalized patients making use of intravenous catheters.

Antibiotic resistance in CoNS has increased over the years and is driven by the acquisition of the mecA gene. The mecA gene is present in more than $80 \%$ of the CoNS late-onset sepsis isolates. Given the large number of methicillin-resistant CoNS, inclusion of vancomycin in empiric therapy for neonates with late-onset septicemia may be justified (Jain et al., 2004). S. haemolyticus has the highest level of antimicrobial resistance among all CoNS species, and heteroresistance to glycopeptides is common (Brodie et al., 2000; Chiew et al., 2007; Froggatt et al., 1989; Sieradzki et al., 1998; Tabe et al., 2001).

In the present study, the disk diffusion tests revealed $90.3 \%$ of the clinical isolates as ORSH. However, the presence of mecA gene was detected only in $77.4 \%$ of $S$. haemolyticus strains independently of oxacillin susceptibility and pulse types. Similar to data described in the literature (Marshall et al, 1998; Zafar Hussain et al., 2000), a categorical agreement between high MICs values and mecA detection was not verified. OSSH strains presenting mecA gene as well as ORSH isolates without mecA gene were observed, among these Brazilian S. haemolyticus nosocomial isolates.

A high proportion (87\%) S. haemolyticus strains isolated from neonates showed multiresistance to antimicrobial agents, including gentamicin used as initial empiric therapy. Microorganisms exhibited different multiresistance profiles independent of pulse types and subtypes; $22.6 \%$ were also resistant to mupirocin. The diversity of high-level mupirocin resistance plasmids [Mup(R)] was also demonstrated in S. haemolyticus strains belonging to different PFGE types or subtypes. (do Carmo Ferreira et al., 2011).

The mechanism of reduced vancomycin susceptibility in CoNS is unclear but may be related to the selection of resistant subpopulations under pressure of antimicrobial exposure (Dunne et al., 2001). In a study made in Japan, the results indicated that methicillin resistance may not be related to reduced susceptibility to glycopeptide in S. haemolyticus and that a multiresistance profile is more associated with a decreasing susceptibility to glycopeptides than with resistance to oxacillin. These facts limit the therapeutic options available and make an ORSH infection a serious threat (Tabe et al., 2001). A reduction in the efficacy of vancomycin has been described in studies of methicillin-resistant $S$. aureus infections treated with this antibiotic, and it has been suggested that slight increases in vancomycin MICs of between 1 and 
$2 \mu \mathrm{g} / \mathrm{mL}$, which are within the susceptible range, may be related to suboptimal clinical outcomes. Some of these studies have used the broth microdilution method for determining vancomycin MICs. Despite the fact that $S$. haemolyticus are usually more resistant to glycopeptides (Ashtiani et al., 2008; Bannerman and Peacock, 2007), the results of our study showed most MICs to vancomycin $\leqslant 4 \mu \mathrm{g} / \mathrm{mL}$ (18 strains). Only 1 strain showed intermediate resistance with MIC $=8 \mu \mathrm{g} / \mathrm{mL}$.

Takeuchi et al. (2005) observed that the highly glycopeptideresistant S. haemolyticus JCSC1435strain frequently generated mutants that lost antibiotic resistance during passage in drug-free medium. JCSC1435 strain may provide an ideal tool for elucidating the genetic mechanisms for acquisition of glycopeptide and $\beta$-lactam antibiotic resistance that poses such a difficult medical problem in modern hospitals. Comparative analysis of the genomes of S. haemolyticus JCSC 1435 strain, S. epidermidis, and S. aureus detected an average sequence identity of $78 \%$ in genes found as orthologues. In that opportunity, complete genome sequencing of S. haemolyticus JCSC1435 uncovered a wide range of open reading frames encoding putative virulence factors. The virulence genes in S. haemolyticus and S. epidermidis were rather "benign" in nature, as indicated by surface adhesins, secretory antigens, serine proteases, and exonucleases (Takeuchi et al., 2005).

Slime production and biofilm formation are important virulence factors of CoNS, allowing them to attach to smooth surfaces of biomaterials; it has been associated with infections of implanted medical devices (Bernardi et al., 2005; Flahaut et al., 2008). Some materials such as glass, hair, and nylon tend to give up electrons and become positively charged. Other materials such as polypropylene, polystyrene, vinyl (PVC), silicon, Teflon, and silicone tend to collect electrons and become negatively charged. Sialic acid may be a constituent molecule of slime and involved in bacterial adherence to inert surfaces, as demonstrated for Corynebacterium diphtheriae (Mattos-Guaraldi et al., 1999) and CoNS (Sakarya et al., 2004). Krepsky et al. (2003) investigated cell surface hydrophobicity and slime production of $S$. epidermidis. Data suggested involvement of protein components in adherence to polystyrene, but not in autoaggregation properties and adherence to glass surfaces. Previous studies also gave an insight into the mechanism of slime production and adherence of slime-forming CoNS to polystyrene plates and polypropylene tubes (Sakarya et al., 2004). Biofilm formation and adherence to acrylic by $S$. haemolyticus were found significantly reduced compared to those of S. epidermidis (Cerca et al., 2004, 2005). Nowadays, biofilm formation is also a common phenotype in clinical S. haemolyticus isolates (Fredheim et al., 2009). In contrast to S. epidermidis, the molecular basis of the virulence of $S$. haemolyticus in general and in the context of foreign material-associated infections is largely unknown. Confocal laser scanning microscopy indicated that the biofilm structure of $S$. haemolyticus clearly differed from that of S. epidermidis (Fredheim et al., 2009).

Several genes have been identified to play roles in the biofilm formation. The ica gene locus (icaADBC) encodes the biosynthesis of polysaccharide intercellular adhesion (PIA), involved in the accumulation process (Heilmann et al., 1996). Fredheim et al. (2009) demonstrated the presence of the ica gene in 3 of $72 \mathrm{~S}$. haemolyticus strains. Hence, a low prevalence compared with the prevalence in S. epidermidis. In concurrence with previously reported sequences, a high degree of similarity between the ica operons was found in different staphylococcal species. Phylogenetic analyses showed that the ica operon of $S$. haemolyticus is closely related to that of S. epidermidis. However, it has become clear that PIA is neither an essential nor necessarily the major component of CoNS biofilms (Fitzpatrick et al., 2005; Kogan et al., 2006; Oliveira and Cunha, 2010). The presence of an ica operon in S. haemolyticus has been reported, but to date, its contribution to biofilm formation is unclear. The biofilmassociated ica locus, present in S. epidermidis and S. aureus, may be absent from clinical isolates of S. haemolyticus (Cerca et al., 2005; De Silva et al., 2002; Fredheim et al., 2009). One of the most novel parts of this present study is the description of a high prevalence (58\%) of the ica-operon in the collection. This separates from other studies where a max prevalence of $1-2 \%$ has been reported. Comparative genome analyses and the possibility to detect genes with higher variation are limited by the fact that there is currently still only 1 fully sequenced genome published (Takeuchi et al., 2005).

Other cell wall structures, such teichoic acid and protein, have been shown to mediate staphylococcal biofilm formation in strains lacking or not expressing the ica locus. A capsular polysaccharide was proposed to be an important virulence factor in S. haemolyticus. However, there was no correlation among the clinical S. haemolyticus isolates between capsular polysaccharide production and biofilm production (Flahaut et al., 2008). Although capsules produced by staphylococci have been detected by changes in colonial appearance, this approach has not been found suitable for determining slime production. The production of slime by CoNS is routinely detected using the Christensen method, although this method may not always be successful for detecting weak slime production. An alternative method for detecting slime that uses a specially prepared solid medium was described by Freeman et al. (1989). CRA was chosen because it has been used as a stain for showing the presence of the exopolysaccharide of bacteria. The exact mechanism of the Congo red phenomenon is as yet unknown.

In the present study, the subtype B2 of S haemolyticus seemed to exhibit a more expressive virulence potential than the other pulse types since it comprised 5 strains with identical phenotypical and genotypical profiles with involvement of all the virulence factors considered in this study. Therefore, all B2 samples were ORSH and exhibited a reduced sensitivity to vancomycin in addition to being carriers of methicillin resistance, adhesion, and biofilm production ( mecA and icaA) genes besides producing biofilm on CRA, polystyrene, and glass. Among the other pulse types, only 2 strains of subtypes B1 and F2 exhibited identical profiles of B2 subtype. Qualitative and quantitative diversity in the ability of biofilm production indicated the involvement of other bacterial and environmental features that need further investigation.

In conclusion, we were able to describe the clonality of ORSH within the NICU in Brazilian hospital and that some clones are endemic in the hospital environment. Measures have to be taken to reduce the risk of hospital-acquired $S$. haemolyticus infections.

The data further suggested that intraspecies differences in virulence occur for S. haemolyticus, as previously described for S. epidermidis (Gunn, 1989). The occurrence of prevalent genotypic groups among the bacteremia isolates of S. haemolyticus may represent strains with higher invasive capacity. The ability to produce biofilm and the notoriously multi-resistance to antimicrobial agents, including glycopeptides, favor S. haemolyticus as an emerging cause of nosocomial infections (Cavanagh et al., 2012). Although S. haemolyticus biofilm formation in vitro has been reported, the molecular mechanisms involved remain partially elucidated. Additional studies of the presence and expression of ica genes may clarify the different adhesion mechanisms in the pathogenesis of S. haemolyticus infections, including those cases associated with medical devices.

\section{Acknowledgments}

This work was supported by grant from CNPq, CAPES, FAPERJ, SR2/UERJ, and Programa de Núcleo de Excelência (PRONEX) of the Brazilian Ministry of Science and Technology. We are grateful to $\operatorname{Dr}^{0}$ Adenilson de Souza da Fonseca from Depart ${ }^{\circ}$ of Biophysics and Biometry of the IBRAG/UERJ, RJ, for assistance in statistical analysis.

\section{References}

Ashtiani MTH, Kamal S, Aboutorabi SK, Mahjoub F, Mamishi S, Asgari F. Comparison of disk diffusion and E test methods for antimicrobial susceptibility testing of 
vancomycin in coagulase negative Staphylococcus isolated from blood culture. Iranian J Pathol 2008;3:61-6.

Baio PV, Mota HF, Freitas AD, Gomes DL, Ramos JN, Sant'Anna LO, et al. Clonal multidrug-resistant Corynebacterium striatum within a nosocomial environment, Rio de Janeiro, Brazil. Mem Inst Oswaldo Cruz 2013;108:23-9.

Bannerman TL, Peacock SJ. Staphylococcus, Micrococcus, and other catalase-positive cocci. In: Murray PR, Baron EJ, Pfaller MA, Jorgensen JH, Landry ML, editors. Manual of Clinical Microbiology. 9th ed. Washington, DC: ASM Press; 2007. p. 390-411.

Barros EM, Ceotto H, Bastos MC, Santos KR, Giambiagi-Demarval M. Staphylococcus haemolyticus as an important hospital pathogen and carrier of methicillin resistance genes. J Clin Microbiol 2012;50:166-8.

Bernardi ACA, Pizzolitto EL, Pizzolitto AC. Detection of slime production by coagulasenegative staphylococci isolated from central venous catheter. J Basic Appl Pharm Sci 2005;22:223-38.

Bjorkqvist M, Soderquist B, Tornqvist E, Sjöberg L, Kühn I, Colque-Navarro P, et al. Phenotypic and genotypic characterization of blood isolates of coagulase-negative staphylococci in the newborn. APMIS 2002;110:332-9.

Botelho AM, Nunes ZG, Asensi MD, Gomes MZ, Fracalanzza SE, Figueiredo AM. Characterization of coagulase-negative staphylococci isolated from hospital indoor air and a comparative analysis between airborne and inpatient isolates of Staphylococcus epidermidis. J Med Microbiol 2012;61(8):1136-45.

Bradford R, Abdul MR, Daley AJ. Coagulase-negative staphylococci in very-low-birthweight infants: inability of genetic markers to distinguish invasive strains from blood culture contaminants. Eur J Clin Microbiol Infect Dis 2006;25:283-90.

Brodie SB, Sands KE, Gray JE, Parker RA, Goldmann DA, Davis RB. Occurrence of nosocomial bloodstream infections in six neonatal intensive care units. Pediatr Infect Dis J 2000;19:56-65.

Cavanagh JP, Klingenberg C, Hanssen A-M, Fredheim EA, Francois P, Schrenzel J, et al. Core genome conservation of Staphylococcus haemolyticus limits sequence based population structure analysis. J Microbiol Methods 2012;89:159-66.

Center for Disease Control and Prevention (CDC). 1993 revised classification system for HIV infection and expanded surveillance case definition for AIDS among adolescents and adults. Morb Mortal Wkly Rep Recomm Rep 1992;41:1-19.

Cerca N, Pier GB, Oliveira R, Azeredo J. Comparative evaluation of coagulase-negative staphylococci (CoNS) adherence to acrylic by a static method and a parallel-plate flow dynamic method. Res Microbiol 2004;155:755-60.

Cerca N, Martins S, Sillankorva S, Jefferson KK, Pier GB, Oliveira R, et al. Effects of growth in the presence of subinhibitory concentrations of dicloxacillin on Staphylococcus epidermidis and Staphylococcus haemolyticus biofilms. Appl Environ Microbiol 2005;71:8677-82.

Chaieb K, Mahdouani K, Bakhrouf A. Detection of icaA and icaD loci by polymerase chain reaction and biofilm formation by Staphylococcus epidermidis isolated from dialysate and needless in a dialysis unit. J Hosp Infect 2005;61:225-30.

Chiew YF, Charles M, Johnstone MC, Thompson KM, Parnell KD, Penno EC. Detection of vancomycin heteroresistant Staphylococcus haemolyticus and vancomycin intermediate resistant Staphylococcus epidermidis by means of vancomycin screening agar. Pathology 2007;39:375-7.

Chu C, Wallace D, Ofoegbu BN, Hassan I. A case of neonatal Eustachian valve endocarditis. J Clin Pathol 2011;64:647-8.

Clinical and Laboratory Standards Institute (CLSI). Performance standards for antimicrobial susceptibility testing - tenth edition supplement (M02-A10). Wayne, PA: CLSI; 2010

Clinical and Laboratory Standards Institute (CLSI). Performance standards for antimicrobial susceptibility testing - eleventh edition supplement (M02-A11). Wayne, PA: CLSI; 2012

De Silva GD, Kantzanou M, Justice A, Massey RC, Wilkinson AR, Day NP, et al. The ica operon and biofilm production in coagulase-negative staphylococci associated with carriage and disease in a neonatal intensive care unit J Clin Microbiol 2002:40:382-8.

Do Carmo Ferreira N, Schuenck RP, Santos KR, de Freire Bastos MC, Giambiagi-de Marval M. Diversity of plasmids and transmission of high-level mupirocin mupA resistance gene in Staphylococcus haemolyticus. FEMS Immunol Med Microbiol 2011;61:147-52.

Dunne Jr WM, Qureshi H, Pervez H, Nafziger DA. Staphylococcus epidermidis with intermediate resistance to vancomycin: elusive phenotype or laboratory artifact? Clin Infect Dis 2001;33:135-7.

Falcone M, Giannella M, Raponi G, Mancini C, Venditti M. Teicoplanin use and emergence of Staphylococcus haemolyticus: is there a link? Clin Microbiol Infect 2006;12:96-7.

Fitzpatrick F, Humphreys H, O'Gara JP. Evidence for icaADBC-independent biofilm development mechanism in methicillin-resistant Staphylococcus aureus clinical isolates. J Clin Microbiol 2005:43:1973-6.

Flahaut S, Vinogradov E, Kelley KA, Brennan S, Hiramatsu K, Lee JC. Structural and biological characterization of a capsular polysaccharide produced by Staphylococcus haemolyticus. J Bacteriol 2008;190:1649-57.

Foka A, Chini V, Petinaki E, Kolonitsiou F, Anastassiou ED, Dimitracopoulos G, et al. Clonality of slime-producing methicillin-resistant coagulase-negative staphylococci disseminated in the neonatal intensive care unit of a university hospital. Clin Microbiol Infect 2006;12:1230-3.

Fredheim EG, Klingenberg C, Rohde H, Frankenberger S, Gaustad P, Flaegstad T, et al. Biofilm formation by Staphylococcus haemolyticus. J Clin Microbiol 2009;47 1172-80.

Freeman DJ, Falkiner FR, Keane CT. New method for detecting slime production by coagulase-negative Staphylococci. J Clin Pathol 1989;42:872-4.

Froggatt JW, Johnston JL, Galetto DW, Archer GL. Antimicrobial resistance in nosocomial isolates of Staphylococcus haemolyticus. Antimicrob Agents Chemother 1989;33: $460-6$.
Fuchs PC, Jones RN, Barry AL. Interpretive criteria for disk diffusion susceptibility testing of mupirocin, a topical antibiotic. I Clin Microbiol 1990:28:608-9.

Gunn BA. Comparative virulence of human isolates of coagulase-negative staphylococci tested in an infant mouse weight retardation model. J Clin Microbiol 1989;27: 507-11.

Heilmann C, Schweitzer O, Gerke C, Vanittanakom N, Mack D, Gotz F. Molecular basis of intercellular adhesion in the biofilm-forming Staphylococcus epidermidis. Mol Microbiol 1996;20:1083-91.

Ing MB, Baddour LM, Bayer AS. Bacteremia and infective endocarditis: pathogenesis, diagnosis, and complications. In: Crossley KB, Archer GL, editors. The staphylococci in human disease. New York, NY: Churchill Livingstone; 1997. p. 331-54.

Iorio NLP, Ferreira RBR, Schuenck RP, Malvar KL, Pereira AB, Nunes APF, et al. Simplified and reliable scheme for species-level identification of clinical isolates of Staphylococcus. J Clin Microbiol 2007;45:2564-9.

Iorio NL, Azevedo MB, Frazão VH, Barcellos AG, Barros EM, Pereira EM, et al. Methicillinresistant Staphylococcus epidermidis carrying biofilm formation genes: detection of clinical isolates by multiplex PCR. Int Microbiol 2011;14(1):13-7.

Jain A, Agarwal J, Bansal S. Prevalence of methicillin-resistant, coagulase-negative staphylococci in neonatal intensive care units: findings from a tertiary care hospital in India. J Med Microbiol 2004;53:941-4.

Kazembe P, Simor AE, Swarney AE. A study of the epidemiology of an endemic strain of Staphylococcus haemolyticus (TOR-35) in a neonatal intensive care unit. Scand J Infect Dis 1993:25:507-13.

Klingenberg C, Rønnestad A, Anderson AS, Abrahamsen TG, Zorman J, Villaruz A, et al. Persistent strains of coagulase-negative staphylococci in a neonatal intensive care unit: virulence factors and invasiveness. Clin Microbiol Infect 2007;13:1100-11.

Kogan G, Sadovskaya I, Chaignon P, Chokr A, Jabbouri S. Biofilms of clinical strains of Staphylococcus that do not contain polysaccharide intercellular adhesin. FEMS Microbiol Lett 2006;255:11-6.

Krepsky N, Ferreira RBR, Nunes APF, Lins UGC, Filho FCS, Mattos-Guaraldi AL, et al. Cell surface hydrophobicity and slime production of Staphylococcus epidermidis Brazilian isolates. Curr Microbiol 2003;46:280-6.

Kumari N, Rai A, Jaiswal CP, Xess A, Shahi SK. Coagulase negative staphylococci as causative agents of urinary tract infections-prevalence and resistance status in IGIMS, Patna. Indian J Pathol Microbiol 2001;44:415-9.

Low DE, Schmidt BK, Kirpalani HM, Moodie R, Kreiswirth B, Matlow A, et al. An endemic strain of Staphylococcus haemolyticus colonizing and causing bacteremia in neonatal intensive care unit patients. Pediatrics 1992;89:696-700.

Marshall SA, Wilke WW, Pfaller MA, Jones RN. Staphylococcus aureus and coagulasenegative staphylococci from blood stream infections: frequency of occurrence, antimicrobial susceptibility, and molecular (mecA) characterization of oxacillin resistance in the SCOPE program. Diagn Microbiol Infect Dis 1998;30:205-14.

Mattos-Guaraldi AL, Cappelli EA, Previato JO, Formiga LCD, Andrade AFB. Characterization of surface saccharides in two Corynebacterium diphtheriae strains. FEMS Microbiol Lett 1999;170:159-66.

Mehta G, Singh S, Kumari S. Observations on coagulase-negative staphylococci in a neonatal unit in India. J Hosp Infect 1991;19:273-81.

Monsen T, Karlsson C, Wistrom J. Spread of clones of multidrug-resistant, coagulasenegative staphylococci within a university hospital. Infect Control Hosp Epidemiol 2005;26:76-80.

Moreira LO, Andrade AFB, Vale MD, Souza SMS, Hirata Jr R, Asad LMB, et al. Effects of iron limitation on adherence and cell surface carbohydrates of Corynebacterium diphtheriae strains. Appl Environ Microbiol 2003;69:5907-13.

Neumeister B, Kastner S, Conrad S, Klotz G, Bartmann P. Characterization of coagulasenegative staphylococci] causing nosocomial infections in preterm infants. Eur J Clin Microbiol Infect Dis 1995;14:856-63.

Nunes APF, Teixeira LM, Bastos CCR, Silva MG, Ferreira RBR, Fonseca LS, et al. Genomic characterization of oxacillin-resistant Staphylococcus epidermidis and Staphylococcus haemolyticus isolated from Brazilian medical centres. J Hosp Infect 2005;59:19-26.

Nystrom B, Ransjo U, Ringertz S, Faxelius G, Tunell R, Ohman G, et al. Colonization with coagulase-negative staphylococci in two neonatal units. J Hosp Infect 1992;22: 287-98

Oliveira A, Cunha ML. Comparison of methods for the detection of biofilm production in coagulase-negative staphylococci. BMC Res Notes 2010;3:260-6.

Potter A, Ceotto H, Giambiagi-deMarval M, Santos KRN, Nes IF, Bastos MCF. The gene bap, involved in biofilm production, is present in Staphylococcus spp. strains from nosocomial infections. J Microbiol 2009;47:319-26.

Sakarya S, Oncu S, Ozturk B, Tuncer G, Sari C. Neuraminidase produces dose-dependent decrease of slime production and adherence of slime-forming, coagulase-negative staphylococci. Arch Med Res 2004;35:275-8.

Santos KRN, Teixeira LM, Leal GS, Fonseca LS, Gontijo-Filho PP. DNA typing of methicillin-resistant Staphylococcus aureus: isolates and factors associated with nosocomial acquisition in two Brazilian university hospitals. J Med Microbiol 1999;48:17-23.

Schuenck RP, Pereira EM, Iorio NL, Santos KR. Multiplex PCR assay to identify methicillin resistance of Staphylococcus haemolyticus. FEMS Immunol Med Microbiol 2008;52:431-5.

Sieradzki K, Villari P, Tomasz A. Decreased susceptibilities to teicoplanin and vancomycin among coagulase-negative methicillin-resistant clinical isolates of staphylococci. Antimicrob Agents Chemother 1998;42:100-7

Stepanovic S, Vukovic D, Davic I, Savic B, Svabic-Vlahovic M. A modified microtiterplate test for quantification of Staphylococcal biofilm formation. J Microbiol Methods 2000;40:175-9.

Tabe Y, Nakamura A, Igari J. Glycopeptide susceptibility profiles of nosocomial multiresistant Staphylococcus haemolyticus isolates. J Infect Chemother 2001;7: $142-7$. 
Takeuchi F, Watanabe S, Baba T, Yuzawa H, Ito T, Morimoto Y, et al. Whole genome sequencing of Staphylococcus haemolyticus uncovers the extreme plasticity of its genome and the evolution of human-colonizing staphylococcal species. J Bacteriol 2005;187:7292-308.

Tuo P, Montobbio G, Vallarino R, Tumolo M, Calevo MG, Massone ML, et al. Nosocomial infection caused by multiresistant staphylococci in a neonatal and pediatric intensive care unit. Pediatr Med Chir 1995;17:117-22.

Van Belkum A, Tassios PT, Dijkshoorn L, Haeggman S, Cookson B, Fry NK, European Society Of Clinical Microbiology and Infectious Diseases (Escmid) Study Group On Epidemiological Markers (Esgem). Guidelines for the validation and application of typing methods for use in bacterial epidemiology. Clin Microbiol Infect 2007;13(Suppl 3):1-46.
Vivoni AM, Diep BA, De-Gouveia-Magalhães AC, Santos KRN, Riley LW, Sensabaugh GF, et al. Clonal composition of Staphylococcus aureus isolates at a Brazilian University Hospital: identification of international circulation lineages. J Clin Microbiol 2006;44:1686-91.

Voronina OL, Kunda MS, Dmitrenko OA, Lunin VG, Gintsburg AL. Development of Staphylococcus haemolyticus multilocus sequencing scheme and its use for molecular-epidemiologic analysis of strains isolated in hospitals in Russian federation in 2009-2010. Zh Mikrobiol Epidemiol Immunobiol 2011;5: 62-7.

Zafar Hussain Z, Stoakes L, Massey V, Diagre D, Fitzgerald V, El Sayed S, et al. Correlation of oxacillin MIC with mecA gene carriage in coagulase-negative staphylococci. J Clin Microbiol 2000;38:752-4. 